\title{
Research on Key Technology of Aeolian Vibration Monitoring of Transmission Line at Low Temperature
}

\author{
LIANG Jianquan ${ }^{1, a, *}$, YU Chunlai ${ }^{1, b}$, WANG Yue ${ }^{1, c}$, GAO Ziwei ${ }^{1, d}$, ZHU Xuecheng ${ }^{1, e},{ }^{\text {d }}$ LI \\ Guoxing ${ }^{1, f}$ and LI Lin ${ }^{1, g}$
}

\author{
${ }^{1}$ State Grid Heilongjiang Electric Power Company Limited Electric Power Research Institute, Xiangjiang \\ Road, Harbin, Heilongjiang Province, China \\ a ljq_hit@163.com, ${ }^{\mathrm{b}}$ 602fish@163.com, ${ }^{\mathrm{c}}$ wangyue_chn@163.com, ${ }^{\mathrm{d}}$ Gaoziwei1979@163.com, \\ e zhuxuecheng2004@163.com, ${ }^{\mathrm{f}}$ lgx616161616161@sins.com, ${ }^{\mathrm{g}}$ lilin77@yeah.net \\ *corresponding author
}

Keywords: low temperature, transmission line, aeolian vibration, on-line monitoring

\begin{abstract}
The precision and reliability of sensors are tested rigorously under the influence of low temperature as on-line monitoring technology sensation unit of transmission lines. In the paper, bending amplitude method was applied in aeolian vibration monitoring devices of transmission lines. Device function and technical parameters were proposed aiming at low temperature operation condition. Meanwhile, aeolian vibration state quantity threshold setting and practical improvement technique of vibration diagnostic method were also analyzed. Therefore, the reliability of monitoring devices was improved. Finally, it was concluded that the research results of the paper were application to application in cold region through test and data analysis.
\end{abstract}

\section{Introduction}

Transmission line state monitoring is an important part of smart grid construction power transmission link. It is an important technical means to realize transmission line state operation overhaul management and improve lean level of production operation management [1][2]. Transmission line meteorological on-line monitoring device realize real-time sensation, monitoring early-warning, analysis diagnosis and trend prediction through various advanced sensor technology, wide-area communication technology and information treatment technology. Its construction and promotion work has positive and far-reaching significance for improving the production management level of power grid company, reinforce state condition inspection auxiliary decisionmaking application, and improve power grid intelligence degree. It is important content for power grid operation system construction and optimization [3]-[5].

In foreign countries, transmission line on-line monitoring technology was systematically studied in the 1990s, such as insulator leakage current on-line monitoring system developed by Australian Red Phase Company. In China, Tsinghua University, Xi'an Jiaotong University, Wuhan University, China Electric Institute, Wuhan High Voltage Research Institute and other scientific research units have carried out research on transmission on-line monitoring technology. The transmission line online monitoring technology with complete functions was developed after 2000. Wherein, GSM popularization and application promoted rapid development of the technology. Remote-distance data transmission problems were solved effectively, and manufacturers engaged in on-line monitoring technology development were increased. Transmission line on-line monitoring was ushered in 2003 and 2004. Since the former products were characterized by poor operation stability, users were lack of experience, effective production information can not be provided for users, etc., on-line monitoring technology of leakage current can not be further promoted[6]. In 2005, China Electric Power Research Institute developed on-line monitoring techniques such as transmission Line icing, wire waving, cable anti-theft, image monitoring, wire temperature measurement, etc. They were gradually promoted and applied in power systems with excellent application effect. In 2008, Southern Ice Disaster proved the necessity and urgency of on-line monitoring technology. It 
also promoted rapid development of on-line monitoring technology.

Currently, normal working temperature scope of transmission Line on-line monitoring devices is generally $-40^{\circ} \mathrm{C} \sim+85^{\circ} \mathrm{C}$. Extremely cold temperature is not included in existing standards under the condition of considering general technical conditions. The winter temperature is below $-30^{\circ} \mathrm{C}$ for long term in Northeast China, Xinjiang, Inner Mongolia and other regions. The extreme temperature may reach $-53{ }^{\circ} \mathrm{C}$. The electric performance and mechanical performance of power transmission and transformation equipment can be directly affected. Therefore, it is difficult to guarantee the reliability of on-line monitoring devices.

\section{Working principles of transmission Line aeolian vibration monitoring device}

Overhead transmission Line guide wire aeolian vibration is a major cause to fatigue and damage of guide wire. Guide wire dynamic bending strain is an important parameter of fatigue and damage. However, it is not practical to directly measure the dynamic bending of the wire under site operation condition. IEEE proposed bending amplitude method on the basis of research and practice for many years [10][11].

Bending amplitude is based on relative amplitude of two points. One point is the terminal contact point $\mathrm{O}$ of the wire guide and wire clamp. The other point is point $\mathrm{b} 89 \mathrm{~m}$ away from point $\mathrm{O}$. The relative lateral amplitude $\mathrm{Yb}(\mathrm{P}-\mathrm{P})$ of point $\mathrm{b}$ and point $\mathrm{O}$ refers to bending amplitude as shown in figure 1. There is an estimated and basically linear relationship between bending amplitude value and dynamic bending strain. The relationship is not related to the vibration frequency and the wire clamp. It is proved by practice that bending amplitude is a simple and practical method to measure guide wire vibration in the wire clamp. The vibration in the point $89 \mathrm{~mm}$ away from the wire clamp is measured. Poffemberger-Swart calculation method is applied for calculating the strain of the wire clamp outlet as shown in formula (1).

$$
\varepsilon=\frac{E_{a}-D-p^{2}-Y_{b}}{e^{-p \cdot m}-I+p-x}
$$

In the formula:

$E_{a}$ - Young modulus of outer wire strands, MPa;

$D$ - wire diameter, $\mathrm{mm} ; x=89 \mathrm{~mm}$;

$Y_{b}$ - vibration peak at $89 \mathrm{~mm}$ - peak value, $\mathrm{mm}$;

$I$ - wire minimum rigidity, $\mathrm{mm}$;

$p$ - testing constant, it is related with wire tension $T$ (unit $\mathrm{N}$ ) and wire flexural rigidity $E \cdot I$ (wire minimum rigidity, unit $\mathrm{N} \cdot \mathrm{m})$ :

$$
p=\sqrt{\frac{T}{E I}}
$$

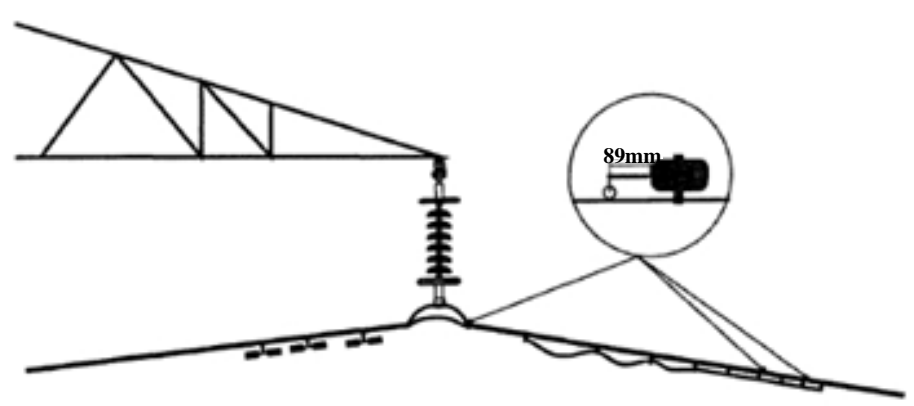

Figure `1 Schematic diagram of bending amplitude method

\section{Functional and technical parameters of aeolian vibration monitoring device at low temperature}

\subsection{Function setting of aeolian vibration monitoring device}

Transmission line aeolian vibration monitoring device includes the following functions: 
(1) Function of data collection

a) Guide wire dynamic bending strain can be calculated and correspondingly stored. The measurement results are transmitted to state monitoring agent device or state monitoring main station system through communication network;

b) The product has function of automatic collection. Wire dynamic bending strain can be automatically collected according to the set time interval. The minimum collection interval should be greater than 5 minutes. The maximum sampling interval should not be more than 15 minutes. The default collection interval is 10 minutes. The record time of each sampling should reach $0.25 \mathrm{~s}$ at least.

c) The product has controlled collection function, which can respond to remote instruction. It can be applied for collecting according to set collection mode, automatic collection time, collection time interval and collection points.

d) The on-line aeolian vibration collection unit should be equipped with the function of collecting power supply voltage, working temperature, etc.

(2) Data processing and discrimination

a) The product has the function of inspecting and analyzing data rationality, the collected data are pre-processed. Interference data were automatically identified and eliminated;

b) The product has the function of calculating original collection quantity by one step. Dynamic bending strain data capable of reflecting aeolian vibration level directly can be obtained.

(3) Data storage: Aeolian vibration state data for at least 30 days can be stored in a cycled mode.

(4) Data output

The output information should include the follows: guide wire amplitude, frequency and other state data as well as working status data, such as power supply voltage, working temperature, heartbeat package, etc.

\subsection{Technical parameters of aeolian vibration monitoring device}

The transmission Line aeolian vibration monitoring device should meet the following parameter requirements:

(1) Application environmental conditions

a) Environment temperature: $-55^{\circ} \mathrm{C} \sim+45^{\circ} \mathrm{C}$ ( low temperature);

b) Relative humidity: 5\% RH $\sim 100 \% \mathrm{RH}$;

c) Atmospheric pressure: $550 \mathrm{hPa} \sim 1060 \mathrm{hPa}$;

(2) Operating temperature: $-55^{\circ} \mathrm{C} \sim+85^{\circ} \mathrm{C}$ (extended industrial grade);

(3) Measurement scope of vibration amplitude

Measurement scope of vibration amplitude of the aeolian vibration collection unit is one of the follows according to the category of the measured guide wire:

a) $0 \sim 0.6 \mathrm{~mm}(\mathrm{p}-\mathrm{p})$;

b) $0 \sim 1.3 \mathrm{~mm}(\mathrm{p}-\mathrm{p})$ 。

(4) Frequency measurement scope: frequency measurement range should be $0 \sim 150 \mathrm{~Hz}$ at least.

(5) Accuracy: Comprehensive error should be less than $10 \%$.

\section{Research on aeolian vibration monitoring key technology at low temperature}

\subsection{Relationship between low temperature and aeolian vibration state quantity threshold selection}

Aeolian vibration monitoring data of Heilongjiang Power Grid Hemu Line B, Fanglin Line Lianhua Reservoir, Xilin Line A and Yongxing Line 1 were combined for checking the dynamic bending strain criteria of 'Q/GDW 245 Technical specifications for transmission Line aeolian vibration monitoring device' appendix B (informative appendix) according to foreign experience and practical experience of domestic wire vibration as shown in table 1 . The threshold of the aeolian vibration dynamic bending strain was kept constant as the judging standard of aeolian 
vibration monitoring.

Table 1 Dynamic bending strain criterion of recommended transmission Line in regions at low temperature

\begin{tabular}{|c|c|c|}
\hline Item & Line long span & Common level \\
\hline Aluminium cable steel reinforced & $\pm 100 \mu \varepsilon$ & $\pm 150 \mu \varepsilon$ \\
\hline $\begin{array}{c}\text { Aluminium-alloy conductor steel-reinforced } \\
\text { aluminium steel stranded cable }\end{array}$ & $\pm 100 \mu \varepsilon \sim \pm 120 \mu \varepsilon$ & $\pm 150 \mu \varepsilon$ \\
\hline Al-clad steel stranded wire and steel cored \\
\hline $\begin{array}{c}\text { Galvanized stranded wire } \\
\text { OPGW (Al-clad steel stranded wire ) } \\
\text { and Al-clad steel stranded wire ) }\end{array}$ & $\pm 150 \mu \varepsilon$ & $\pm 200 \mu \varepsilon$ \\
\hline
\end{tabular}

The following conclusion was obtained through the analysis according to the transmission Line anti-vibration standards:

1) The dynamic bending strain allowable value should not be more than $\pm 150 \mu \varepsilon$ aiming at aluminum stranded conductor and aluminium-alloy conductor, including aluminium cable steel reinforced and aluminium-alloy conductor steel-reinforced. The dynamic bending strain allowable value should not be more than $\pm 200 \mu \varepsilon$ aiming at Al-clad steel stranded wire and steel cored aluminium steel stranded cable. The dynamic bending strain allowable value should not be more than $\pm 300 \mu \varepsilon$ aiming at galvanized stranded wire.

The dynamic bending strain allowable value should not be more than $\pm 150 \mu \varepsilon$ aiming at OPGW (aluminum alloy or aluminum alloy and Al-clad steel stranded wire). The dynamic bending strain allowable value should not be more than $\pm 200 \mu \varepsilon$ aiming at OPGW (Al-clad steel stranded wire).

3) The dynamic bending strain allowable value should not be more than $\pm 100 \mu \varepsilon$ aiming at aluminium cable steel reinforced for the sake of safety with regard to large-span wire and ground electrode. The dynamic bending strain allowable value should not be more than $\pm 100 \mu \varepsilon \sim \pm 120$ $\mu \varepsilon$ aiming at aluminium-alloy conductor steel-reinforced. The dynamic bending strain allowable value should not be more than $\pm 150 \mu \varepsilon$ aiming at Al-clad steel stranded wire and steel cored aluminium steel stranded cable. The dynamic bending strain allowable value should not be more than $\pm 200 \mu \varepsilon$ aiming at galvanized stranded wire.

4) The dynamic bending strain allowable value should not be more than $\pm 120 \mu \varepsilon$ aiming at OPGW (aluminum alloy or aluminum alloy and Al-clad steel stranded wire). The dynamic bending strain allowable value should not be more than $\pm 150 \mu \varepsilon$ aiming at OPGW (Al-clad steel stranded wire).

\subsection{Practicability improvement of aeolian vibration diagnostic method at low temperature}

There were many factors affecting wire aeolian vibration intensity, such as line environmental conditions, span length, suspension point height, wire tension, wire material and structure mode, wind speed and direction, hanging hardware and tower structure, vibration control facilities, electrical wire fatigue limit, fatigue life, etc.

Aeolian vibration monitoring data of Heilongjiang Power Grid Hemu Line B, Fanglin Line Lianhua Reservoir, Xilin Line A and Yongxing Line 1 were combined according to foreign experience and domestic practical experience in wire vibration. The influence of different environment temperatures on wire aeolian vibration can be ignored. Therefore, the aeolian vibration fatigue life calculation and early warning of guide wire at normal temperature were also applicable to that at low temperature. The evaluation of wire vibration life referred to measurement of vibration at key parts of line, such as pendency wire clamp outlet and vibration control equipment 
clamp point outlet. Corresponding relationship between strain level and vibration frequency can be utilized for wire fatigue damage calculation and wire fatigue service life. The marginal vibration frequency was obtained according to and foreign practical experience for checking the dynamic bending strain criteria of 'Q/GDW 245 Technical specifications for transmission Line aeolian vibration monitoring device' appendix B (informative appendix) according to wohler curve. CIGRE fatigue life analysis and CIGRE safety boundary life were combined for quantitative evaluation.

The practical measures to improve the aeolian vibration diagnosis method at low temperature include the follows:

1) Layout plan of the aeolian vibration monitoring device at low temperature can be further optimized, such as pendency wire clamp outlet, vibration control equipment clamp point, vibration damper chuck outlet, etc. Windward side, high hanging point, upper wire, ground electrode, etc. were considered. Wherein, at least one monitoring point was set for ground electrode, upper wire, uptake wire.

2) The maximum value of aeolian vibration amplitude was analyzed according to vibration data of engineering completion site vibration measurement of vibration prevention plan aiming at largespan aeolian vibration monitoring plan at low temperature. Large-span monitoring plan was prepared in a targeted mode.

\section{Field test and data analysis}

There are two neighboring spans in Mohe Qiaobei Xilin Line A Substation, namely 66kV Xilin Line A No. 52 tower-No. 51 tower and No. 51 tower-No. 50 tower, wherein the terminal tower is No. 52 with the model of 66SJJ3 and nominal height of $18 \mathrm{~m}$. No. 51 tower model is 66SJJ1 with normal height of $24 \mathrm{~m}$. No. 50 tower model is $66 \mathrm{SZ2} \_30$, with normal height of $30 \mathrm{~m}$, wire model is LGJ-150/25 with outer diameter of $17.1 \mathrm{~mm}$. The span of No. 50 and No. 51 is $351 \mathrm{~m}$. The span of No. 51 and No. 52 is $155 \mathrm{~m}$. Since the line belongs to double-tower and double loop. The outage plan belong to one-loop outage and one-loop electrified operation. The project is equipped with two transmission Line aeolian vibration on-line monitoring devices in order to ensure construction safety for field electrified installation.

Table 2 Information table of field on-line monitoring device in Mohe

\begin{tabular}{|c|c|c|c|c|c|c|}
\hline No. & Line name & $\begin{array}{c}\text { Tower } \\
\text { number }\end{array}$ & Device type & $\begin{array}{c}\text { Equipment } \\
\text { No. }\end{array}$ & $\begin{array}{c}\text { Sim } \\
\text { card }\end{array}$ & Device number \\
\hline 1 & $\begin{array}{c}\text { 66kVXilinji } \\
\text { Line A }\end{array}$ & $52 \#$ & $\begin{array}{c}\text { Vibration, } \\
\text { sag and } \\
\text { microclimate }\end{array}$ & 1238 & $\begin{array}{c}138 \\
4578 \\
2617\end{array}$ & $\begin{array}{c}\text { Upper wire vibration monitoring } \\
\text { instrument 2493; middle wire vibration } \\
\text { monitoring instrument 2494; lower wire } \\
\text { vibration monitoring instrument 2495; }\end{array}$ \\
\hline 2 & $\begin{array}{c}\text { 66kVXilinji } \\
\text { Line A }\end{array}$ & $51 \#$ & $\begin{array}{c}\text { Vibration, } \\
\text { sag and } \\
\text { microclimate }\end{array}$ & 1239 & $\begin{array}{c}138 \\
4578 \\
2615\end{array}$ & $\begin{array}{c}\text { Upper wire vibration monitoring } \\
\text { instrument 2496; middle wire vibration } \\
\text { monitoring instrument 2503; }\end{array}$ \\
\hline
\end{tabular}

The vibration measurement data by No. 2493 monitor during measurement is shown in Figure 2. The test results show that aeolian vibration is within $\pm 1 \sim \pm 30 \mu \varepsilon$ scope, which is lower than the allowable value of the wire dynamic bending strain. 


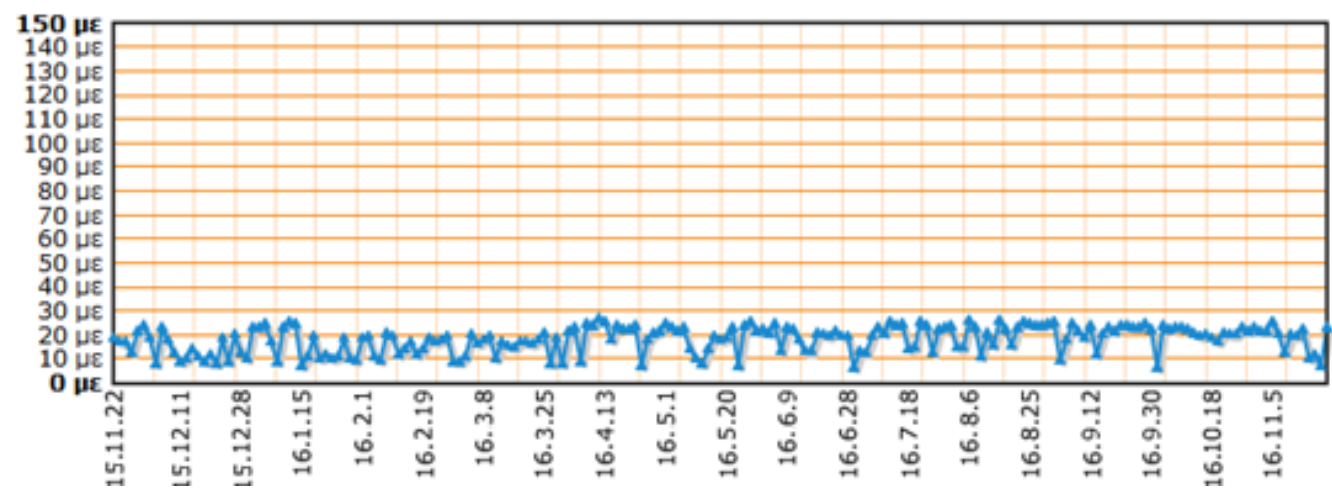

Figure 2 Amplitude curve data of No. 2493 monitor (2015.11.22-2016.11.5)

The vibration measurement data by No. 2494 monitor during measurement is shown in Figure 3. The test results show that aeolian vibration is within $\pm 1 \sim \pm 30 \mu \varepsilon$ scope, which is lower than the allowable value of the wire dynamic bending strain.

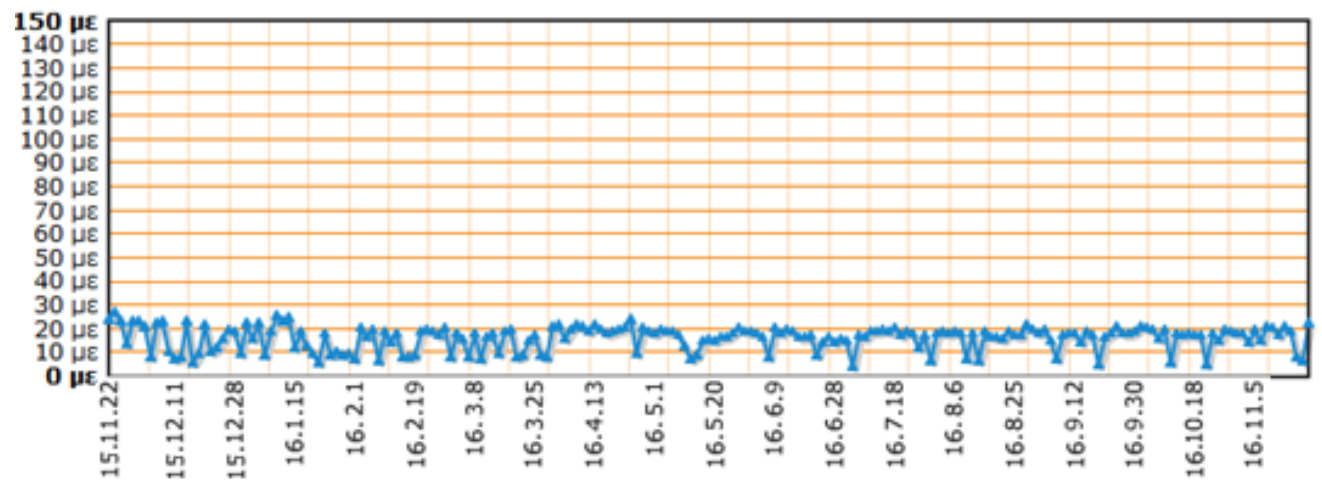

Figure 3 Amplitude curve data of No. 2494 monitor (2015.11.22-2016.11.5)

The vibration measurement data by No. 2495 monitor during measurement is shown in Figure 4. The test results show that aeolian vibration is within $\pm 1 \sim \pm 55 \mu \varepsilon$ scope, which is lower than the allowable value of the wire dynamic bending strain.

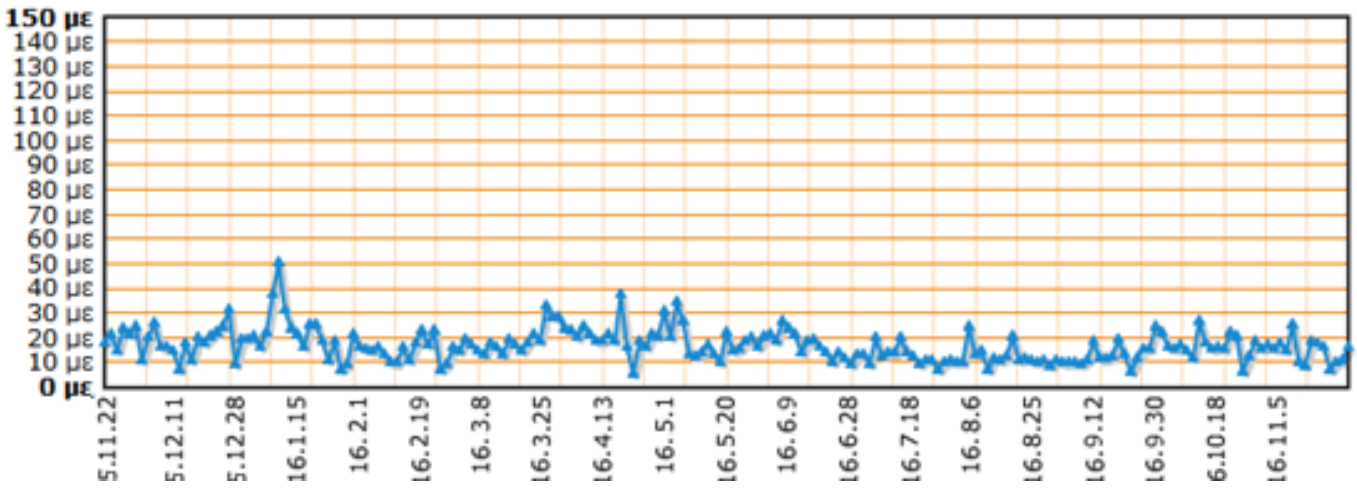

Figure 4 Amplitude curve data of No. 2495 monitor (2015.11.22-2016.11.5)

The vibration measurement data by No. 2496 monitor during measurement is shown in Figure 5. The test results show that aeolian vibration is within $\pm 1 \sim \pm 50 \mu \varepsilon$ scope, which is lower than the allowable value of the wire dynamic bending strain. 


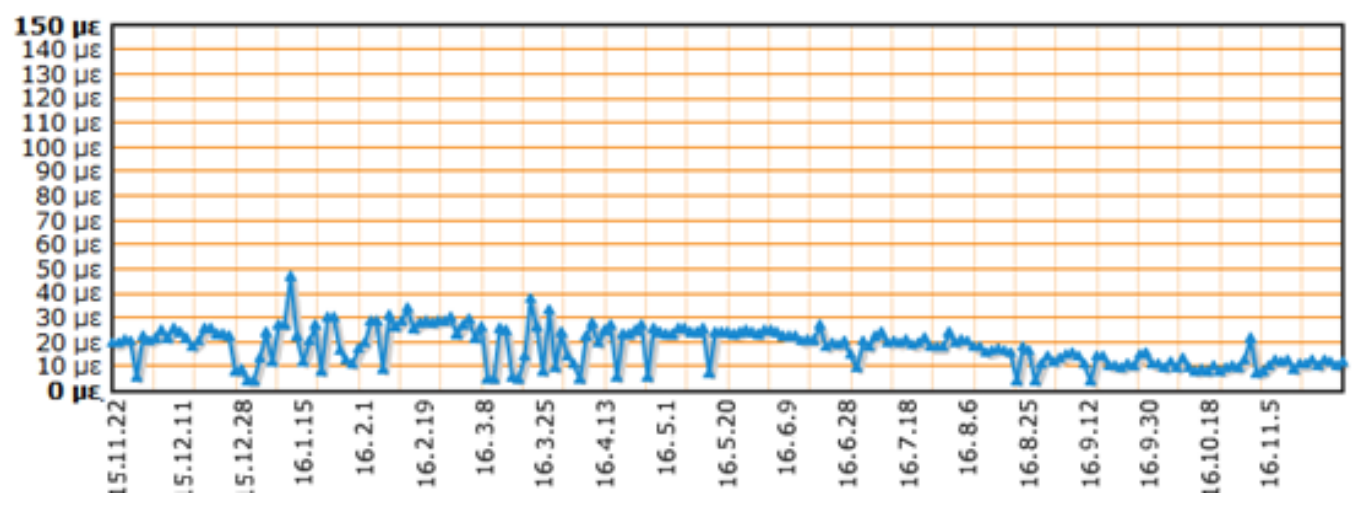

Figure 5 Amplitude curve data of No. 2496 monitor (2015.11.22-2016.11.5)

The vibration measurement data by No. 2503 monitor during measurement is shown in Figure 6 . The test results show that aeolian vibration is within $\pm 1 \sim \pm 40 \mu \varepsilon$ scope, which is lower than the allowable value of the wire dynamic bending strain.

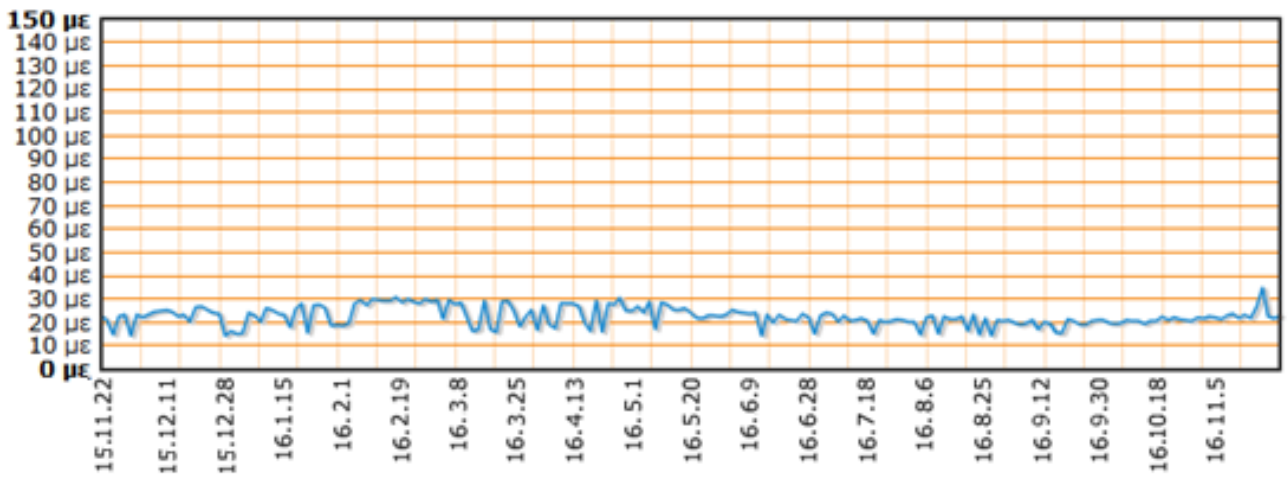

Figure 6 Amplitude curve data of No. 2503 monitor (2015.11.22-2016.11.5)

\section{Conclusion}

The characteristics in cold regions are combined for studying key technologies of wire aeolian vibration at low temperature. Functions of aeolian vibration monitoring device at low temperature and technical parameters that should be satisfied. Field test shows that the research results in the paper are applicable to application in the aeolian vibration monitoring device at low temperature.

There are rare research results on low temperature in domestic and even foreign project application because of limitation of experimental conditions. Actual measurement at different conditions is realized with continuous development of monitoring technology. Low temperature performance of transmission Line tower, wire, hardware and other parts will be further studied deeply. More detailed and concrete wind prevention measures can be established on the basis of studying anti-wind damage in cold regions. System anti-wind equipment can be developed.

\section{References}

[1] NIU Yuzhong, YANG Zhe, Zhang Chunlong. Summarization of Transmission Line on-line Monitoring System[J]. Electric Switchgear, 2017, (02): 1-3.

[2] HUANG Xinbo, ZHANG Guoqi. Status quo Analysis of Online Monitoring Techniques of Transmission Lines[J]. Guangdong Electric Power, 2009, 22(1): 13-20+34.

[3] WANG Guosheng, LIANG Ruiling, SHU Yingjun. Reliability Evaluation Method of Transmission Line On-line Monitoring[J]. Insulators and Surge Arresters, 2013, (04): 89-93.

[4] SUN Fengjie, ZHAO Mengdan, LIU Wei, FAN Jieqing. Study on the On-line Monitoring Technology of Overhead Power Transmission Lines[J]. Southern Power System Technology, 2012, 
(04):17-22.

[5] LIU Lirong, WANG Yudong, XIAO Zhihong, etl. Study on the Communication Transmission Mode of Power Transmission Line Monitoring System[J]. Telecommunications for Electric Power System, 2011, (04):20-25.

[6] ZHANG Zhenqi, SUN Tingxi, YUAN Yongyi. Operation of On line Monitoring of HV Transmission in 2003 Spring at Zhuhai[J]. High Voltage Engineering, 2003, (12):48-51.

[7] QI Shuwen, GAO Shan, LIANG Xiaoliang. On-line Fault Monitoring System of Overhead Transmission Lines Based on GPRS Technology[J]. Jilin Electric Power, 2008, (02):45-46.

[8] NIU Yuzhaong, GUO Yuandong, HUANG Jinzhu. Design and Application of Transmission Line Monitoring System[J]. Electrical \& Energy Management Technology, 2017, (11):64-68.

[9] CHEN Haibo, WANG Cheng, LI Junfeng, etl. Application of On-line Monitoring Technologies for UHV AC Transmission Lines[J]. Power System Technology, 2009, (10):55-58.

[10] CHEN Jian, HUANG Zhijie, LI Luping, etl. Fretting damage characteristics of overhead electrical conductors[J]. Electric Power, 2004, (10):35-37.

[11] ZHANG Huitao. A New Method for Field Measuring Breeze Vibration on Transmission Lines[J]. Electric Power, 1999,(12):62-65. 